\title{
INTERSECCIONALIDADE GÊNERO, RAÇA E ETNIA E A LEI MARIA
} DA PENHA

\author{
INTERSECCIONALIDAD GÉNERO, RAZA Y ETNIA Y LA LEY MARIA \\ DA PENHA \\ GENDER, RACE AND ETHNICITY INTERSECTIONALITY AND MARIA DA \\ PENHA'S LAW
}

\author{
Raquel da Silva Silveira e Henrique Caetano Nardi \\ Universidade Federal do Rio Grande do Sul, Porto Alegre/RS, Brasil
}

\begin{abstract}
RESUMO
A violência de gênero contra as mulheres é um fenômeno mundial abordado exaustivamente. Este artigo discute como a interseccionalidade gênero, raça e etnia emerge nos discursos jurídicos sobre as mulheres que acessam a justiça. O referencial teórico foi composto pela analítica do poder de Michel Foucault articulada aos conceitos de interseccionalidade, gênero, raça e etnia. A pesquisa de campo foi realizada no Poder Judiciário de Porto Alegre e de Sevilha entre agosto de 2010 e outubro de 2012. Foram construídas três amostras de conveniência: entrevistas com 290 mulheres, análise de 70 processos judiciais e de 55 boletins de ocorrência. Foram realizadas entrevistas com quatro juízes/as de Porto Alegre e dois juízes em Sevilha. Os resultados apontam uma sobrerrepresentação das mulheres negras nos boletins de ocorrência, nas entrevistas, mas não nos processos. Apesar disso, os/as juízes/as entrevistados/as compreendem que a interseccionalidade gênero-raça e etnia não interfere no acesso à justiça.
\end{abstract}

Palavras-chave: violência doméstica; interseccionalidade; raça e etnia; Direitos Humanos; políticas públicas.

\section{RESUMEN}

La violencia de género contra las mujeres es un fenómeno mundial discutido a fondo. En este artículo se discute como la interseccionalidad género, raza y etnia emerge en los discursos legales sobre las mujeres que buscan el acceso a la justicia. El marco teórico fue compuesto por la analítica del poder de Michel Foucault articulada a los conceptos de interseccionalidad, género, raza y etnia. La pesquisa de campo fue realizada en el Poder Judiciário de Porto Alegre y de Sevilla, entre agosto de 2010 y octubre de 2012. Se construyeron tres amuestras de conveniencia: entrevistas con 290 mujeres, análisis de 70 procesos judiciales y de 55 informes policiales. Se construyeron entrevistas con cuatro jueces/as de Porto Alegre y dos jueces en Sevilla. Los resultados apuntan una sobrerrepresentación de las mujeres negras. Sin embargo, los/as jueces/as entrevistados/as comprehenden que la interseccionalidad género-raza y etnia no afecta el acceso a la justicia.

Palavras clave: violencia doméstica; interseccionalidad; raza y etnia; Derechos Humanos; políticas públicas.

\begin{abstract}
Gender-based violence against women is a worldwide phenomenon extensively studied. This article discusses how intersectionality between gender, race and ethnicity emerges in legal discourse about women accessing justice. The theoretical framework was composed by Michel Foucault's power analytics articulated with the concepts of intersectionality, gender, race and ethnicity. The fieldwork was conducted from August 2010 to October 2012 in Porto Alegre's and Seville's judiciary system. Quantitative and qualitative research techniques were used to analyze convenience samples composed by 70 lawsuits, 55 police reports and 290 interviews with women victims. Interviews were also conducted with four judges of Porto Alegre and two judges of Seville. The results indicate an overrepresentation of black women in police reports and interviews but not in law suits. Nevertheless, in judges' answers, gender-race-ethnicity intersectionality is not recognized as an element interfering in the access to justice.
\end{abstract}

Keywords: domestic violence; intersectionality; race and ethnicity; Human Rights; public policies. 
A temática da interseccionalidade entre gênero, raça e etnia nas situações de violência de gênero contra as mulheres nas relações de intimidade (Smigay, 1989) tem sido pouco explorada. Essa constatação embasa-se no levantamento de estado da arte, bem como na análise das práticas discursivas presentes no Poder Judiciário de Porto Alegre (RS), principalmente após a promulgação da Lei Maria da Penha em 2006. Desde 2004, desenvolvemos uma parceria interinstitucional e interdisciplinar entre $o$ Programa de Pós-Graduação em Psicologia Social e Institucional da UFRGS e o Curso de Direito do UniRitter. A partir de 2005, começamos a desenvolver projetos de extensão junto à Delegacia da Mulher e ao Poder Judiciário.

Nesse contexto, produzimos uma pesquisa em articulação com ações extensionistas cujo objetivo foi analisar as práticas discursivas do campo jurídico sobre a interseccionalidade gênero, raça e etnia e seus efeitos na produção de subjetividade no que tange à violência de gênero contra as mulheres nas relações de intimidade. Nosso trabalho se situa na intersecção das políticas públicas, dos direitos humanos e das práticas do judiciário no campo da violência de gênero. A partir do referencial teórico de Michel Foucault (1973/2005), compreendemos que o campo jurídico produz discursos com efeito de verdade que são fundamentais na produção de subjetividade. Para tanto, realizamos um estudo comparativo entre duas legislações, a Lei Maria da Penha (2006) e a Lei de Proteção Integral à Violência de Gênero da Espanha (2004). A pesquisa de campo foi desenvolvida nas cidades de Porto Alegre, Canoas e Sevilha. Em Porto Alegre, trabalhamos em três locais: Delegacia da Mulher, Juizado de Violência Doméstica e Familiar contra a Mulher e ONG Maria Mulher. Na cidade de Canoas, produzimos informações a partir de atendimentos do Serviço de Atendimento Judiciário (SAJUIR) do UniRitter. A metodologia de trabalho integrou uma ação de extensão universitária de atendimentos interdisciplinares a mulheres que buscaram os dois órgãos públicos citados. $\mathrm{O}$ trabalho de campo se deu entre agosto de 2010 e outubro de 2012. Foram utilizados recursos de pesquisa quantiqualitativos em três amostras de conveniência. No juizado foram analisados 70 processos judiciais. $\mathrm{Na}$ Delegacia da Mulher foram analisados 55 boletins de ocorrência, além de 290 entrevistas com mulheres vítimas de violência. Também foram realizadas entrevistas com quatro juízes/as do referido juizado de Porto Alegre, dois juízes na cidade de Sevilha e uma militante negra nigeriana residente há 26 anos em Sevilha. Na cidade de Canoas analisamos um caso de violência interseccional.
O objetivo deste artigo é apresentar alguns resultados de nossa análise que indicam a forma como os discursos jurídicos brasileiros e espanhóis têm negligenciado essa problemática. $\mathrm{O}$ intuito desta escrita é contribuir para práticas mais efetivas em psicologia social, reforçando a necessidade da interdisciplinaridade para o enfrentamento da violência de gênero contra as mulheres nas relações de intimidade.

\section{A caixa de ferramentas conceituais: gênero, interseccionalidade, raça e etnia}

Pesquisar de forma interdisciplinar e extensionista o tema da violência de gênero contra as mulheres nas relações de intimidade exige uma caixa de ferramentas ampla. Quando se agregam a essa temática os estudos da interseccionalidade racial e étnica, o objeto de pesquisa se expande em complexidade. $\mathrm{O}$ recurso metodológico de empreender uma análise comparativa com a Espanha foi sustentado pelas propostas de Robert Castel (1995/2001) sobre a importância de que os grandes problemas sociais sejam discutidos a partir de uma perspectiva internacional. Assim, a comparação com outras sociedades permite descentramentos do olhar (Nardi, 2008), que por sua vez potencializam o reconhecimento de que a produção dos saberes científicos é fruto de saberes localizados (Haraway, 1995). Contudo, esses saberes precisam estar atentos à organização do mundo globalizado, pois as políticas públicas locais inscrevem-se nesse contexto político maior.

Por isso, tecemos aqui alguns fios que nos ajudaram a compor a colcha de retalhos conceituais com que operamos. Dentre a profícua discussão teórica sobre o conceito de gênero, elegemos estudiosas como Joan Scott (1988/1995), Judith Butler (1990/2003) e Donna Haraway (1991/1995). Essas autoras permitem compreender o gênero de forma complexa, aberto a múltiplas negociações, não limitado à lógica do patriarcado. Por concordarmos com a proposição de Donna Haraway (1995) de que os saberes sempre são localizados, apropriamo-nos dos trabalhos de Heleieth Saffioti (2009) e de Sueli Carneiro (2005). Essas autoras feministas explicitam aspectos interseccionais de classe e de raça que produzem arranjos singulares na violência de gênero contra as mulheres na sociedade brasileira. $\mathrm{O}$ conceito de gênero tem sido utilizado como instrumento de análise para desnaturalizar e deslegitimar as práticas de violência e de opressão que constituíram a vida das mulheres, bem como das pessoas que não se encaixam na norma heterossexual. Segundo Judith Butler (1990/2003, p. 24), gênero foi 
inicialmente compreendido como "os significados culturais assumidos pelo corpo sexuado", produzindo uma dicotomia entre sexo (biologia) e gênero (cultura), a qual foi desconstruída pelo feminismo da terceira onda. Joan Scott apontou ser o gênero o primeiro exercício de poder sobre os nossos corpos. Todavia, esse exercício de poder não é o único que nos constitui. Logo emergiram proposições teóricas que sustentaram a existência de três grandes marcadores sociais que atravessam a produção de subjetividade: a classe, o gênero e a raça. Segundo Heleieth Safiotti (2009, p. 82), "mais do que papéis sociais que se aprende nos processos de socialização, são as identidades sociais (gênero, raça e etnia, classe) que vão gestando a subordinação, a partir das experiências vividas que colocam as mulheres nesse lugar". Para Safiotti (2009), as formas de dominação e de exploração se inscrevem num enovelado de fios composto por gênero-raçaclasse.

Em consonância com essas formulações teóricas, o movimento feminista de mulheres negras potencializou a visibilização dos impactos do marcador racial na produção de subjetividade. Dessa forma, o conceito de interseccionalidade passou a produzir rachaduras nos discursos que focalizavam apenas uma vertente de diferenciação social, a classe. Segundo Kimberlé Crenshaw (2002, p. 177), “a interseccionalidade é uma conceituação do problema que busca capturar as consequências estruturais e dinâmicas da interação entre dois ou mais eixos de subordinação". Essa autora propõe que os eixos de poder estabelecidos pelo patriarcado, pelo racismo e pela luta de classes se cruzam como avenidas em que o fluxo do tráfego define a multiplicidade de opressões às quais a pessoa estará submetida.

Apontamos a importância dos estudos de Avtar Brah (1996/2005) em propor que se utilizasse o conceito de articulação ao invés de interseccionalidade. Essa autora fez uma crítica à interseccionalidade, por compreender que o conceito carrega certa fixidez em visibilizar em demasia as subordinações que o encontro de marcadores como gênero e raça produz. Avtar Brah salienta que também podem ocorrer resistências e formas inusitadas nesses arranjos. Mesmo cientes dessa crítica direcionada ao conceito de interseccionalidade, ao finalizarmos esta pesquisa, avaliamos que, para o nosso recorte investigativo, o conceito de interseccionalidade era mais adequado. A interseccionalidade entre gênero, raça e etnia nas situações de violência contra as mulheres nas relações de intimidade é um campo atravessado por relações de dominação, as quais se encontram num momento importante de tensionamentos, mas que ainda são marcadas por muita desigualdade e opressão. Assim sendo, trabalhamos com o conceito de interseccionalidade, priorizando a experiência na forma como as pessoas vão constituindo-se no jogo de forças a que estão expostas.

Importante salientar que, ao acolhermos as expressões de dominação-exploração utilizadas de forma alternada, mas sempre juntas, por Safiotti (2009), uma vez que a autora compreende a dimensão econômica e política como constitutivas das relações sociais, mas sem primazia de uma sobre a outra, não as tomamos como vetores de pura submissão, mas sim enquanto relações de poder na perspectiva de Michel Foucault (1995). Para Foucault, as relações de poder constituem o campo de possibilidades dos modos de subjetivação no interior dos quais se articulam os processos de resistência (intrínsecos a essa compreensão de poder). Para esse autor, o conceito de produção de subjetividade compreende a vida como efeito de um campo de possibilidades marcado por jogos de verdade que potencializam determinadas formas de nos constituirmos como sujeitos. Nessa perspectiva, o sujeito não é visto como uma unidade psicológica "autônoma", mas como um ser inscrito numa trama histórica que lhe oferece as condições para a construção de si no registro do social. Para Michel Foucault (1995, p. 235), a palavra sujeito carrega dois significados: "sujeito a alguém pelo controle e dependência, e preso à sua própria identidade por uma consciência ou autoconhecimento. Ambos sugerem uma forma de poder que subjuga e torna sujeito a". Assim, a subjetividade é tomada como uma produção histórica, localizada no tempo e no espaço, a partir de complexas relações atravessadas pelos saberes disponíveis que objetificam o que somos. Esses saberes são fruto dos embates específicos próprios às formas de dominação de cada época, as quais são marcadas por práticas de resistência também específicas. Essa perspectiva se assenta na premissa de Foucault de que só existem relações de poder quando há liberdade; assim, a resistência deve ser compreendida como intrínseca às formas de dominação.

Em relação aos conceitos de raça e de etnia, ambos são utilizados nos jogos de poder, seja na instauração de formas de dominação, seja na sustentação das lutas de resistência (Munanga, 2008). O conceito de raça carrega uma longa trajetória (Wade, 2001), que no século XIX culminou com a produção teórica do racismo científico. Essa teoria legitimava a superioridade da raça branca europeia e a inferioridade das demais raças humanas, sendo que a raça negra ocupava o último nível nessa hierarquização biológica. Depois dos horrores do nazismo, houve uma crítica 
radical à utilização do conceito de raça. No campo teórico, Lilia Schwarcz (2001) é uma das autoras que sustenta a ideia de que mesmo que o conceito raça já tenha sido desconstruído do ponto de vista biológico, ele ainda é um potente conceito descritivo e analítico das relações sociais. Para Antônio Guimarães (2008, p. 77), a categoria raça é "um conceito sociológico, certamente não realista, no sentido ontológico, pois não reflete algo existente no mundo real, mas um conceito analítico nominalista, no sentido de que se refere a algo que orienta e ordena o discurso sobre a vida social".

Por outro lado, o conceito de etnia aborda as questões de identidade dos povos, e nem sempre expressa relações de dominação. Segundo Fredrik Barth (1969/1998), nessa conceituação é fundamental o estabelecimento de fronteiras de diferenciação, em que a questão cultural é central. Outro ponto característico do conceito de etnia é a questão do lugar de origem, pontuado por Peter Wade (2001). Dessa maneira, compreendemos que na sociedade brasileira o conceito de etnia é coerente para os estudos sobre as populações indígenas e não para a população negra.

Assim sendo, amparamo-nos em estudos que sustentam a permanência de diferenças conceituais entre raça e etnia. Entendemos que no Brasil o conceito de raça é pertinente para análises das relações entre a população branca e a população negra, principalmente porque não se pode falar de diferenças culturais entre esses grupos, e sim de relações de exploração, de dominação, de discriminação e de privilégios das pessoas brancas com relação às pessoas negras.

$\mathrm{Na}$ sociedade espanhola, a categoria interseccionalidade gênero/raça tem sido utilizada para analisar as desigualdades no campo do trabalho. Em virtude do grande número de imigrantes que procuram a Espanha, Carlota Puig (2009) demonstra como em meados dos anos 1990 se intensificaram os processos de "internacionalização da reprodução". O trabalho doméstico parece ser uma das únicas possibilidades de trabalho para as mulheres imigrantes, independente de suas trajetórias individuais e níveis de escolarização. Esse estudo aponta que os "trabalhos de mulheres" menos valorizados, tanto o doméstico quanto a prostituição, acabam sendo a porta de entrada das mulheres oriundas da região Sul do globo para os países do Norte. Segundo María Lugones (2008), o conceito de interseccionalidade permite que se veja o que não seria visível caso as categorias de gênero e de raça fossem conceitualizadas de forma separada. Para essa autora, o "sistema moderno-colonial de gênero" produziu nas mulheres não-brancas um processo dual de subordinação de gênero e de inferiorização racial.
Além das limitações de trabalho enfrentadas pelas mulheres imigrantes, as recorrentes condições de imigração ilegal produziram maiores dificuldades de enfrentamento das situações de violência de gênero nas relações de intimidade. Assim, em 2009, o Estado espanhol editou o Plano Nacional de Atenção e Prevenção de Violência em Mulheres Imigrantes, bem como uma legislação específica de proteção às mulheres imigrantes vítimas de violência de gênero. Dessa maneira, expandiram-se direitos que eram destinadas apenas às mulheres cidadãs espanholas (Carbó, 2009).

Nesse cruzamento entre imigração e raça, é interessante pontuar que, por ser a Espanha um país colonizador, produziu-se uma imagem de certa "pureza" racial na população espanhola. Em um estudo sobre as mulheres negras na Espanha (Vives \& Sité, 2010), constatou-se a dificuldade de reconhecerem uma pessoa negra como cidadã espanhola. As pessoas negras sempre são vistas e tratadas como imigrantes africanas, mesmo que tenham nascido em território espanhol e sido subjetivadas na cultura espanhola. Dentro desse contexto de um imaginário mais "puro" do ponto de vista racial, em que a raça branca é predominante, a temática do racismo tem sido subvalorizada na Espanha. Em contrapartida, existe o reconhecimento de que há discriminações e vulnerabilidades pela questão étnica e pela imigração. No eixo da etnia, a cultura cigana é uma parte significativa da população espanhola que, por preservar as especificidades de sua cultura, acaba encontrando dificuldades de integração nos padrões da Europa ocidental (RED2RED, 2011).

Assim, ainda que a questão da imigração seja um marcador social da interseccionalidade de gênero no contexto espanhol atual, o reconhecimento da utilidade do conceito de etnia se faz presente, principalmente porque as comunidades ciganas constituem o traçado característico populacional da cidade de Sevilha, sendo o grupo mais marginalizado e vulnerável. Naquele coletivo, as diferenças que importam não estão inscritas na cor da pele, apesar de alguns traços fenotípicos específicos da população cigana. Contudo, são os aspectos culturais que definirão seu estatuto no imaginário espanhol. Interessante pontuar que a população cigana classifica os espanhóis, as espanholas e as pessoas que não são ciganas como "payos", numa exemplificação daquilo que Barth (1969/1998) caracterizou como um dos elementos da etnicidade, qual seja, a incorporação em cada grupo étnico do compartilhamento no processo de reconhecimento das diferenças. A comunidade cigana se caracteriza por ser altamente patriarcal, e as mulheres se situam numa posição muito vulnerável nas relações de intimidade. 
Entretanto, e até mesmo em razão desse traço cultural, as ciganas raramente acessam o Poder Judiciário para buscar proteção contra a violência de gênero. Existe um silenciamento teórico-político sobre a violação de direitos humanos desse coletivo de mulheres na temática aqui focalizada, sob a alegação de que realçar a vulnerabilidade das mulheres produziria maior estigmatização dessa população.

\section{Refletindo sobre os efeitos da interseccionalidade gênero, raça e etnia}

Nas Américas, num estudo comparativo sobre raça, etnia e saúde reprodutiva entre Brasil, México e Colômbia, Livio Sansone (2004) descreve a flexibilidade e permeabilidade dos conceitos de raça e etnia, justamente por serem vetores que constituem as identidades das pessoas. Segundo ele, "a identidade étnica e a racialização fazem parte de um processo geral de redefinição de identidades sociais e da posição do indivíduo na sociedade" (Sansone, 2004, p. 60). Além da utilização simultânea do conceito de etnicidade e de racialização, esse autor destaca um ponto importante para o foco desta pesquisa, que é a inter-relação entre identidade étnica e identidade de gênero: "Em muitos aspectos, o gênero é a lente a partir da qual a identidade étnica é vivenciada. Certas etnicidades e racializações correspondem a um uso específico do corpo, muitas vezes à transmissão de imagens associadas à sexualidade" (Sansone, 2004, p. 90).

No campo da saúde, José Laguardia (2004) destaca a importância de inclusão efetiva de análise da variável raça, pois existem desigualdades de saúde na população que são atravessadas pelos racismos institucionais. Ele aponta a necessidade de que os/as pesquisadores/as acolham o conceito "raça" para além do tradicional individualismo biomédico, passando a apropriar-se dos conhecimentos científicos sobre os fatores e os processos sociais que estão subjacentes às desvantagens sociais, as quais foram produzidas historicamente. Esse autor ressalta como as restrições de ordem macroestrutural impostas às pessoas acabam por condicionar comportamentos em saúde. De acordo com Laguardia (2004, p. 223), "as consequências psicossociais e econômicas decorrentes do preconceito e da discriminação racial são causas fundamentais da desigualdade em saúde". Isso acontece porque o racismo é constitutivo da produção de subjetividade brasileira, a qual é marcada pelo ideário de superioridade das pessoas brancas.

Para Simone Monteiro (2004), os estudos epidemiológicos que identificam maior prevalência de alguns adoecimentos na população negra utilizam a categoria raça em sua dimensão de marcador social. Dentre os fatores que identificam a maior frequência de algumas patologias em pessoas negras estão o estresse psicológico e a baixa autoestima. Esses são sintomas relacionados a fatores sociais de desigualdades e discriminação, que acabam gerando a "falta de equidade social, inclusive na saúde" (Monteiro, 2004, p. 48). Além disso, ela destaca que a questão racial interfere no acesso e nas formas de interação da população negra com os serviços de saúde, produzindo maior vulnerabilidade para alguns adoecimentos.

Com relação à mortalidade das porto-alegrenses em idade fértil, no período entre 2001 e 2008, houve certa estabilidade nos índices das mulheres brancas, com uma redução em 2008, que ficou em 36,0/10.000. Contudo, houve um aumento significativo desse tipo de mortalidade entre as mulheres negras, passando de $57,4 / 10.000$ para 74,7/10.000. Esse estudo também apresenta informações do relatório Saúde Brasil 2005 do Ministério da Saúde, o qual produziu informações com o quesito raça/cor. "No caso da assistência prénatal verificou-se que $62 \%$ das mães de nascidos brancos referiam ter passado por sete ou mais consultas de pré-natal, e somente $37 \%$ das mães de nascidos negros referiram esta oportunidade" (Prefeitura Municipal de Porto Alegre, 2010, p. 5).

Cabe lembrar que em recente decisão internacional do Comitê das Nações Unidas para Eliminação da Discriminação contra Mulheres (CEDAW - 49 a sessão, julho/2011), o estado brasileiro foi considerado responsável pela morte de Alyne da Silva Pimentel Teixeira, 28 anos, grávida de seis meses. Ela faleceu devido à negligência e à demora no atendimento médico-hospitalar diante das complicações de sua gravidez. Houve a compreensão de que se tratou de um caso de violação de direitos da mulher, no qual a discriminação racial e econômica contribuiu para o desfecho fatal, pois se tratava de uma mulher negra e pobre. Esse foi o primeiro caso de mortalidade materna analisado internacionalmente. Além disso, visibilizou a importância que o conceito de interseccionalidade vem produzindo na luta pelos Direitos Humanos ${ }^{2}$.

Sueli Carneiro (2005) é uma das autoras que tem salientado os impactos do racismo na população brasileira, sustentando que a negritude brasileira tem vivido sob o signo da morte. Corroborando essa perspectiva teórica, os dados do Mapa da Violência de 2012 (Waiselfisz, 2012, p. 14) apontam um percentual maior de vitimização da população negra do que da população branca, sendo esse percentual de 132,3\%: "Isto é, para cada branco vítima de homicídio 
proporcionalmente morreram 2,3 negros pelo mesmo motivo". Esse é um dado nacional. Quando feita a análise pelos estados da federação, encontramos dados alarmantes, como nos estados da Paraíba e Alagoas, em que as proporções são de 1 branco para 19 negros e 1 branco para 18 negros, respectivamente. Com um recorte geracional, a pesquisa verificou que a vitimização de jovens negros é ainda maior, em nível nacional, aumentando o percentual para $153,9 \%$, ou seja, "morrem proporcionalmente duas vezes e meia mais jovens negros que brancos" (Waiselfisz, 2012, p. 39).

Uma escuta atenta dessas informações a fim de que se transformem em conhecimento pode produzir desassossegos no olhar hegemônico da branquitude científica. O conceito de branquitude analisa os benefícios simbólicos e materiais de se ser branco/a numa sociedade racista (Bento, 2009). A branquitude produz uma "transparência" na experiência de vida das pessoas brancas, como se a branquitude de seus corpos fosse a norma, ficando a percepção das questões raciais minimizada. Assim, como a maioria das pessoas que ocupam as melhores posições de trabalho e culturais é branca, a branquitude se afirma como a norma e a negritude emerge como seu avesso: a diferença (Schucman, 2012). Historicamente, essa diferença racial foi naturalizada como hierárquica, moral, física e socialmente. No Brasil, essa naturalização da dominação branca foi possível graças ao mito da democracia racial (Guimarães, 2008), produzindose um período de negação sobre os efeitos dessa diferenciação na produção de subjetividade.

Segundo Maria Jesus de Moura (2009), ainda que exista a coleta de informação sobre a questão racial nos protocolos de atendimento da saúde, os/as profissionais não reconhecem que essa informação seja relevante, pois sequer pensaram sobre isso. Os psicólogos e as psicólogas entrevistados/as em sua pesquisa demonstraram ausência de reflexão teórica sobre os impactos da negritude na constituição subjetiva.

Nos protocolos de atendimento da justiça, o marcador racial também é coletado e, assim como na saúde, não produz nenhum efeito de reflexão. Para avançarmos nos objetivos desta pesquisa, buscamos amparo no conceito de "burocracia do nível da rua", de Michael Lipsky (1980/2010). Esse conceito permite analisar como as práticas desenvolvidas na linha de frente dos atendimentos à população interferem na execução das políticas públicas. Esse autor propôs esse conceito nos anos de 1980, nos EUA, com o objetivo de descrever as ações desenvolvidas pelos/as funcionários/ as que executam as políticas públicas. Essas pessoas possuem um alto grau de discricionariedade, pois são elas que decidem os encaminhamentos burocráticos, distribuindo benefícios ou sanções para os/as cidadãos/ ãs. A importância desse conceito reside no fato de ele ser potente para pensar o contato do público com os serviços, um lugar privilegiado de análise da forma como vivemos, no dia a dia, a experiência do governo da vida, ao qual estamos subordinados/as pelas políticas de Estado. A burocracia do nível da rua é executada pelos/as trabalhadores/as de ponta, ou seja, aqueles/as que atendem diretamente às pessoas que acessam os serviços públicos.

Nessa discussão teórica norte-americana (Lipsky, 1980/2010), um aspecto diferenciador com o contexto brasileiro é o quanto essa perspectiva é explícita em relação aos conflitos raciais. Em diversos momentos da análise da burocracia do nível da rua, Lipsky aponta o racismo dos atores sociais, salientando, por exemplo, o racismo dos/as policiais, que costumam tratar de forma diferenciada brancos/as e negros/as. Esse tipo de análise não é frequente nas teorias brasileiras, exceto naquelas que se dedicam à temática do racismo e das relações raciais.

Essa ausência da discussão racial no campo teórico brasileiro pode ser vista como um dos efeitos do dispositivo da racialidade nos nossos regimes de verdade. Amparada nas discussões da analítica do poder de Michel Foucault, Sueli Carneiro (2005) propôs que o exercício do biopoder nas sociedades modernas configurou, além do dispositivo da sexualidade (Michel Foucault), o dispositivo da racialidade. A partir da dinâmica foucaultiana, essa autora compreende que, no Brasil, o dispositivo da racialidade está inscrito nos regimes de verdade através das táticas do segredo e do silêncio, sustentando os exercícios do biopoder. Assim, Sueli Carneiro (2005, p. 33) afirma que o silenciamento da questão racial possibilita a "compreensão da dinâmica discursiva que enfeixa as relações raciais no Brasil na qual os silêncios têm lugar privilegiado".

Dessa forma, quando trabalhamos com a violência de gênero contra as mulheres nas relações de intimidade, é preciso compreender que muitos fios tecem a sua complexidade. Na temática do gênero, é fundamental assegurarmos a perspectiva de violação de Direitos Humanos, um problema público, portanto, e não "só" privado. Trata-se de produção de subjetividade, ou seja, algo de ordem coletiva, e não individual. Entretanto, quando os/as burocratas do nível da rua não abordam seriamente os impactos que o racismo e a subordinação econômica/social produzem em sua articulação com as desigualdades de gênero, compreendemos que existe o risco de um retorno a 
uma visão individualizadora desse tipo de violência contra as mulheres.

\section{Violência de gênero contra as mulheres e interseccionalidade racial e étnica. "Aqui esse problema não existe!"}

A violência de gênero contra as mulheres nas relações de intimidade é um fenômeno mundial que tem sido abordado exaustivamente. A maioria dos estudos que discute essa temática é enfática em apontar que ela acontece em todas as classes sociais, em todas as culturas, independente de raça, de etnia, de idade, de religião ou de qualquer outro marcador de diferenciação. Entendemos que esse enunciado teve seu valor para consolidação de um forte conjunto de medidas políticas que uniram forças em prol de denunciar as vulnerabilidades a que o conjunto das mulheres do mundo estava exposto. Todavia, o tema da igualdade entre as pessoas não é algo fácil de conquistar, e logo emergiram discussões teóricopolíticas que apontavam a fragilidade desse enunciado sobre a universalidade da categoria mulher como um sujeito coletivo e homogêneo, mostrando as diferenças nas relações de poder entre as mulheres.

O percurso desta pesquisa permitiu reconhecermos uma negação e um silenciamento sobre a interseccionalidade da violência de gênero com os marcadores sociais de raça e de etnia. Essa foi uma constatação que emergiu nos espaços judiciários nas duas cidades investigadas, tanto em Porto Alegre como em Sevilha. Nas entrevistas com os/as quatro juízes/as de Porto Alegre, bem como com os dois juízes entrevistados na cidade de Sevilha, encontramos um consenso de que a questão racial e étnica não produz interseccionalidade com esse tipo de violência. Além dos momentos de entrevistas, foi recorrente escutarmos de outros/as burocratas do nível da rua o enunciado: "aqui esse problema não existe". Em alguns salões de iniciação científica em sessões do campo jurídico nas quais esta pesquisa foi apresentada, houve inclusive comportamentos hostis por parte de algumas bancas, os quais podem ser lidos como resistência de deslocamento do dispositivo da racialidade, principalmente pelos efeitos da branquitude nas bancas examinadoras, exclusivamente compostas por pessoas brancas. Cabe lembrar que todos/as os juízes/as entrevistados/as também eram brancos/as. A negação sobre a interseccionalidade entre as desigualdades sociais brasileiras e as relações sociais discriminatórias entre a população branca e a população negra (preta e parda) é uma das estratégias centrais do dispositivo da racialidade. Reconhecer os privilégios de se ser branco/a em nossa sociedade é um dos requisitos para desassossegar a produção subjetiva da universalidade que a categoria de "homem branco" carrega.

A partir de nossa atuação em ações de extensão, a temática da interseccionalidade gênero/raça tem sido abordada nos espaços de assistência jurídica. Assim, no ano de 2012, chegou ao Sajuir/UniRitter ${ }^{3}$ uma senhora negra, com idade de 60 anos, que foi pedir auxílio para a situação de violência que vinha vivendo. Ela já estava separada de fato de uma relação conjugal de quatro anos e queria encaminhar um pedido de pensão e de partilha de bens. Na primeira entrevista com os/as estudantes de direito que prestavam a assistência judiciária gratuita, ela apresentava sinais físicos da violência e estava muito nervosa. Dessa forma, uma professora foi chamada para acompanhar o atendimento. Durante seu relato sobre as diversas cenas de humilhações e violação de direitos que havia experimentado na relação conjugal, aquela senhora comentou que às vezes era ofendida de "negra", "macaca", e "que não servia para outra coisa que não fosse satisfazer seus (do companheiro branco) caprichos" (conforme relatado no processo judicial). Esse comentário estava integrado de forma naturalizada na fala da "vítima", e só ganhou visibilidade porque essa professora não deixou que aquele enunciado desaparecesse. Ao interromper a "cliente", pediu que ela explicasse melhor aquela cena de violência verbal. Segundo relato da docente, apesar de visivelmente entristecida com as situações de violência que vinha relatando, foi somente nesse momento de focalização no racismo vivido que a senhora "desabou" e caiu em prantos. Em virtude disso, fomos atrás do processo físico para ver como isso seria tratado no judiciário gaúcho. A nossa equipe jurídica tinha registrado nos autos processuais a violência de gênero e racista, a qual foi classificada como "injúria", porém, o processo foi direcionado para a regularização das questões de Direito de Família. Em todo o percurso de trabalho de campo, essa foi a única vez que tivemos a oportunidade de ver a interseccionalidade expressa explicitamente na cena íntima de violência de gênero. Contudo, essa violência interseccional foi apenas citada, mas não entrou na argumentação jurídica para exigir algum tratamento processual. No prosseguimento de análise daquele processo, verificamos que na resposta argumentativa da defensoria pública, em defesa do réu, houve o enfrentamento da temática, afirmando que aquele homem, branco, "sempre teve em seu convívio pessoas negras e seu gosto pessoal foi sempre por mulheres afro-descendentes", e, portanto, jamais a havia ofendido. Depois disso, há um documento intitulado Declinação de Competência, 
em que a representante do Ministério Público afirma que: "O Ministério Público entende que, no caso, não há interesse público a justificar a sua intervenção, pois a lide versa apenas sobre questão de estado de partes maiores e capazes". O primeiro posicionamento do juiz foi conceder o benefício da AJG (Assistência Judiciária Gratuita). Assim sendo, nenhum comentário sobre a violência interseccional de gênero e raça foi tecido pelas autoridades no processo. Não satisfeitos/as com o desfecho de apagamento da situação, decidimos acompanhar a primeira audiência daquele processo para ver se haveria alguma retomada da questão. Como imaginávamos, nenhuma palavra sobre o tema foi proferida. Cabe destacar que a peça jurídica inicial foi elaborada por um estagiário do Núcleo da Mulher do Sajuir, porém a advogada do Sajuir que estava na audiência centrou seu trabalho nos quesitos solicitados de Direito de Família, nos quais não constava nenhum pedido sobre a "injúria" racista. Além disso, por tratarse de uma Vara de Família para discutir as questões patrimoniais envolvidas, bem como o pedido de pensão que ela fazia, tampouco a violação de direitos assegurados pela Lei Maria da Penha foi tocada. Mais de uma vez aquela senhora foi informada de que ali, na Vara de Família, o objetivo era outro; não era o local/ competência jurídica para se falar sobre violência de gênero contra as mulheres nas relações de intimidade.

Diante desse silenciamento da violação de direitos interseccionais que a "objetividade" da lei produz, nos perguntamos sobre os espaços de escuta e de acolhimento que têm sido oferecidos no campo da saúde antes de simplesmente encaminharmos as mulheres "vítimas" de violência à Delegacia da Mulher. Estudos apontam que nem sempre os/as profissionais do campo da saúde estão preparados/as para compreender a articulação entre a violação de direitos e seus impactos na saúde (Monteiro, 2004; Moura, 2009).

Voltando ao nosso foco de pesquisa, quando foram realizadas as entrevistas com os/as juízes/as, a primeira pergunta era sobre se concordavam ou não com o enunciado de que a violência de gênero contra as mulheres nas relações de intimidade é universal. A resposta sempre foi de concordância. Depois eram questionados/as se não reconheciam que outras variáveis poderiam interferir, como a questão racial e étnica, por exemplo. De novo respostas unânimes de que não. Então se tensionava sobre a possibilidade de que o acesso à justiça fosse diferente, e novamente a resposta era de negativa: "Esse é um problema universal, assim como o acesso à justiça é universal”.

Em Sevilha havia a experiência compartilhada de quase não haver mulheres negras nas audiências.
Um dos juízes brincou que talvez os homens africanos fossem menos violentos, pois quando eles compareciam como réus nos processos de venda ilegal nas ruas eram sempre muito humildes e educados. Os dois juízes diziam que havia muitas mulheres latino-americanas, mas que o problema maior era o alcoolismo dos homens. Quanto à ausência de mulheres ciganas no acesso ao Poder Judiciário em virtude da violência de gênero, os juízes entendiam que era uma cultura que não se submete à regulação do Estado. Quando tensionados sobre a diferença de acesso das mulheres negras imigrantes, eles foram unânimes em dizer que elas eram protegidas por legislações especiais, bem como com auxílio de tradutores/as quando necessário, e, portanto, o acesso era igual.

Em contrapartida, quando discutimos esse tema com a militante negra nigeriana que vive há 26 anos em Sevilha, ela discordou do posicionamento dos juízes entrevistados e disse que há muita violência sim contra as mulheres africanas, mas que as imigrantes experimentam diversos entraves para acessar a justiça, principalmente de ordem moral. Além de terem sido subjetivadas em culturas altamente patriarcais, sendo que em muitos países de origem não há nem mesmo a igualdade jurídica formal, a maioria das famílias imigrantes tem obrigação moral e material de contribuir com as famílias que ficaram na África. Nesse contexto, pedir a interferência do Estado para protegê-las das violências vividas torna-se um caminho quase intransponível. Quanto às mulheres ciganas, essa informante comentou que eram muito fechadas mesmo, que nem sequer se articulavam com os movimentos feministas.

Diante da circulação nos espaços judiciários do enunciado de que a interseccionalidade étnica e racial não se relaciona com a violência de gênero contra as mulheres nas relações de intimidade, nem mesmo no acesso à justiça, procuramos aprimorar o nosso olhar investigativo para as informações quantiqualitativas que esta pesquisa produziu. Assim, o primeiro movimento foi analisar a distribuição racial das mulheres nas três amostras e comparar com os dados do Censo brasileiro.

De acordo com os dados do IBGE/Censo de 2010, Porto Alegre apresenta a seguinte distribuição racial: $79,23 \%$ da população se autodeclara como branca, e $20,24 \%$ da população se autodeclara como negra (pretas + pardas). Dessa forma, esperávamos um percentual de mulheres brancas em todas as amostras da pesquisa de campo similar à distribuição racial desta capital. Contudo, somente nos processos judiciais em andamento constatamos essa similaridade, conforme a Figura 1. 
Figura 1 - Comparação da Distribuição Racial nas três amostras desta pesquisa

\begin{tabular}{|c|c|r|r|c|}
\hline RAÇA & $\begin{array}{c}\text { IBGE/Censo 2010 } \\
\text { Porto Alegre }\end{array}$ & $\begin{array}{c}\text { AMOSTRA } \\
\text { Processos }\end{array}$ & $\begin{array}{c}\text { AMOSTRA } \\
\text { Boletins de } \\
\text { Ocorrência }\end{array}$ & $\begin{array}{c}\text { AMOSTRA } \\
\text { Atendimentos- } \\
\text { Entrevitas }\end{array}$ \\
\hline Branca & $79,23 \%$ & $77,6 \%$ & $63,6 \%$ & $56,1 \%$ \\
\hline Negra & $20,24 \%$ & $22,4 \%$ & $36,4 \%$ & $42,0 \%$ \\
\hline
\end{tabular}

Chamou-nos a atenção que nos boletins de ocorrência e nos atendimentos realizados às mulheres na Delegacia e no Juizado o percentual de mulheres negras é muito superior à distribuição da raça negra na cidade de Porto Alegre. Destacamos, por exemplo, o percentual de mulheres que foram atendidas nesta pesquisa, em que $42 \%$ delas se autodeclararam negras, sendo que a população autodeclarada negra em Porto Alegre é de 20,24\%. Ou seja, encontramos mais que o dobro da representação dessas mulheres, num fenômeno que é considerado pela literatura $\mathrm{e}$ pelos juízes/as entrevistados/as como universal, sem diferenciação racial. Esses dois locais, a Delegacia e o Juizado, estavam em fase preliminar de solicitação e deferimento de medidas protetivas, em que era possível o arquivamento do processo, sem a realização da denúncia-crime. Nesse sentido, acreditamos que a visibilização dessa diferença na distribuição racial das amostras desta pesquisa permite que se questione o enunciado de que a raça não tem relevância, que não interfere e tampouco que não aparece nas situações de violência de gênero contra as mulheres nas relações de intimidade.

Se na experiência do cotidiano das práticas policiais e judiciais o marcador social da raça não é percebido, assim como também nossa equipe não conseguia identificar grandes diferenças entre mulheres brancas e negras no percurso da pesquisa de campo, quando se produz uma análise interseccional percebese a materialidade das diferenças que fazem diferença. Levando em consideração a distribuição racial na cidade de Porto Alegre, encontramos sim um percentual muito maior de mulheres negras que iniciaram o percurso de acesso à justiça para cessar as situações de violência de gênero nas relações de intimidade. Essa informação sugere o prosseguimento de pesquisas que problematizem essa maior incidência de mulheres negras como "vítimas" desse tipo de violência. Além disso, identificamos que cai pela metade a quantidade de mulheres negras na continuidade dos processos judiciais, indicando que não há paridade entre a raça branca e a raça negra nos níveis mais avançados de acesso à justiça.

\section{Reflexões finais}

Temáticas complexas como a violência de gênero contra as mulheres nas relações de intimidade exigem aprofundamento teórico e sensibilidade por parte daqueles/as que irão atuar nessa área. As mulheres que procuram auxílio do Poder Judiciário e da segurança pública para cessar as situações de violência na privacidade de suas vidas, normalmente já percorreram outros caminhos na busca de solução, mas com dificuldades de concretizar as mudanças desejadas.

Nesse sentido, é fundamental estarmos aptos/as a compreender que as vivências de submissão feminina foram gestadas na longa trajetória das relações sociais, sendo a igualdade formal entre homens e mulheres algo que nem sempre se efetiva nas experiências de intimidade. Além disso, agregar a noção de interseccionalidade dos marcadores raciais e étnicos na constituição de múltiplas violações de direitos é imprescindível para práticas jurídicas e psicológicas que problematizem a desigualdade material no acesso à justiça, bem como no acesso aos equipamentos da saúde. O famoso jargão de que "cada caso é um caso", pode, de fato, se beneficiar do conceito da interseccionalidade para produzir um olhar atento às desigualdades que constituem as experiências singulares de cada mulher. Num país constituído pela escravidão e pelo racismo, é fundamental 
transcendermos a transparência da branquitude da maior parte dos/as profissionais do direito e da psicologia, com o consequente reconhecimento de que as mulheres negras vivenciam diferentes formas de acessar seus direitos.

Finalizamos esta escrita reafirmando a importância de aproximar o debate teórico-político entre Brasil e Espanha, com o intuito de contextualizar a luta das mulheres em nível internacional. Esse esforço demonstra que existem diferentes estratégias políticas para enfrentarmos as práticas sociais que reforçam a dominação masculina e que, por tratar-se de um tema universal de violação de direitos humanos, a violência de gênero contra as mulheres nas relações de intimidade ainda impõe a necessidade de pesquisas acadêmicas e da construção de políticas públicas efetivas e eficazes.

\section{Notas}

1 De acordo com o "Diccionario de la lengua española - Real Academia Española (2001, p. 1706), "payo" significa: "entre os ciganos, quem não pertence a sua raça".

2 A decisão completa pode ser acessada em: http:// reproductiverights.org/sites/crr.civicactions.net/files/ documents/Alyne\%20v.\%20Brazil\%20Decision.pdf

3 Centro Universitário Ritter dos Reis - Laureate International Universities.

\section{Referências}

Barth, F. (1998). Grupos étnicos e suas fronteiras. In P. Poutignat \& J. Streiff-Fenart, Teorias da Etnicidade (E. Fernandes, Trad., pp. 187-227) São Paulo: UNESP. (Original publicado em 1969)

Bento, M. A. S. (2009). Branqueamento e branquitude no Brasil. In I. Carone \& M. A. S. Bento (Orgs.), Psicologia social do racismo: estudos sobre branquitude e branqueamento no Brasil (4a ed., pp. 25-58). Petrópolis, RJ: Vozes.

Brah, A. (2005). Cartographies of diaspora: Contesting identities. New York: Routledge. (Original publicado em 1996)

Butler, J. (2003). Problemas de gênero: feminismo e subversão da identidade (R. Aguiar, Trad.). Rio de Janeiro: Civilização Brasileira. (Original publicado em 1990)

Carbó, P. A. (2009). Mujeres inmigradas que padecen violencia en la pareja y sistema socio jurídico: encuentros y desencuentros. Portularia, 9(1), 33-46.

Carneiro, A. S. (2005). A construção do outro como não-ser como fundamento do ser. Tese de Doutorado, Programa de Pós-Graduação em Educação, Universidade de São Paulo, São Paulo.

Castel, R. (2001). As metamorfoses da questão social: uma crônica do salário (I. D. Poleti, Trad.) Petrópolis, RJ: Vozes. (Original publicado em 1995)

Crenshaw, K. (2002). Documento para o encontro de especialistas em aspectos da discriminação racial relativos ao gênero (L. Schneid, Trad.). Revista Estudos Feministas, 10(1), 171-188.

Foucault, M. (2005). A verdade e as formas jurídicas (R. C. M. Machado \& E. J. Morais, Trads.). Rio de Janeiro: NAU Editora. (Original publicado em 1973)

Foucault, M. (1995). O sujeito e o poder. In: P. Rabinow \& H. Dreyfus, Michel Foucault, uma trajetória filosófica: para além do estruturalismo e da hermenêutica (V. P. Carrero, Trad.). Rio de Janeiro: Forense Universitária.

Guimarães, A. (2008). Raça, cor e outros conceitos analíticos. In O. Pinho \& L. Sansone (Orgs.), Raça-novas perspectivas antropológicas (pp. 63-82). Salvador: EDUFBA.

Haraway, D. (1995). Ciência, cyborgs y mujeres: La reinvención de la naturaleza (M. Talens, Trad.). Madrid: Cátedra. (Original publicado em 1991)

Instituto Brasileiro de Geografia e Estatística - IBGE. (2010). Indicadores Sociais Municipais: uma análise dos resultados do universo do Censo Demográfico 2010 (Estudos e Pesquisas: Informação Demográfica e Socioeconômica, 28). Rio de Janeiro: Autor. Acesso em 02 de junho, 2014, em http://biblioteca.ibge.gov.br/visualizacao/livros/liv54598. pdf

Laguardia, J. (2004). O uso da variável "raça" na pesquisa em saúde. PHYSIS: Revista Saúde Coletiva, 14(2), 197-234.

Lei 11.340, de 7 de agosto de 2006. (2006, 8 de agosto). Lei Maria da Penha. Diário Oficial da União, Seção 1, p. 1.

Ley Orgánica 1/2004, de 28 de diciembre. (2004, 29 de diciembre). Medidas de Protección Integral contra la Violencia de Género. BOE, 313, 42166-42197. Acesso em 02 de junho, 2014, em http://www.boe.es/diario_boe/txt. php?id=BOE-A-2004-21760

Lipsky, M. (2010). Street-Level Bureaucracy: Dilemas of the individual in Public Services. New York: Russel Sage Foundation. (Original publicado em 1980)

Lugones, M. (2008, Julio/diciembre). Colonialidad y género. Tabula Rasa, 9, 73-101.

Monteiro, S. (2004). Desigualdades em saúde, raça e etnicidade: questões e desafios. In S. Monteiro \& L. Sansone (Orgs.), Etnicidade na América Latina: um debate sobre raça, saúde e direitos reprodutivos (pp. 45-56). Rio de Janeiro: Editora FIOCRUZ.

Moura, M. J. (2009). A produção de sentidos sobre a violência racial no atendimento psicológico a mulheres que denunciam violência de gênero. Dissertação de Mestrado, Programa de Pós-graduação em Psicologia, Universidade Federal de Pernambuco, Recife.

Munanga, K. (2008). Rediscutindo a mestiçagem no Brasil: identidade nacional versus identidade negra. Belo Horizonte: Autêntica.

Nardi, H. C. (2008). O estatuto da diversidade sexual nas políticas de educação no Brasil e na França: a comparação como ferramenta de desnaturalização do cotidiano de pesquisa. Psicologia \& Sociedade, 20(n. spe.), 12-23.

Prefeitura Municipal de Porto Alegre. (2010). Boletim Epidemiológico (Edição Especial - População Negra), ano 12, 44. Acesso em 21 de maio, 2014, em http://lproweb. procempa.com.br/pmpa/prefpoa/observatorio/usu_doc/ boletim_pop_negra2010.pdf

Puig, C. (2009). Las trayectorias sociales de las mujeres inmigrantes no comunitárias em España. Factores explicativos de la diversificación de la mobilidad laboral intrageneracional. Barcelona: Instituto de la Mujer. 
RED2RED. (2011). Panel sobre discriminación por origem racial o étnico (2010): la percepción de las potenciales víctimas. Madrid: Ministerio de Sanidad, Política Social e Igualdad.

Saffioti, H. (2009). Ontogênese e filogênese do gênero: ordem patriarcal de gênero e a violência masculina contra mulheres. Série Estudos/Ciências Sociais/FLASCO-Brasil. Acesso em 15 de maio, 2014, em http://www.flacso.org.br/portal/pdf/ serie estudos ensaios/Heleieth_Saffioti.pdf

Sansone, L. (2004). "Raça”. Etnicidade e saúde reprodutiva: o caso afro-latino-americano. In S. Monteiro \& L. Sansone (Orgs.), Etnicidade na América Latina: um debate sobre raça, saúde e direitos reprodutivos (pp. 57-96). Rio de Janeiro: Editora FIOCRUZ.

Schucman, L. V. (2012). Entre o “encardido”, o “branco" $e$ o "branquíssimo”: raça, hierarquia e poder na construção da branquitude paulistana. Tese de Doutorado, Programa de Pós-Graduação em Psicologia, Universidade de São Paulo, São Paulo.

Schwarcz, L. (2001). Racismo no Brasil. São Paulo: Publifolha.

Scott, J. (1995). Gênero: uma categoria útil para a análise histórica (G. L. Louro, Trad.). Educação \& Realidade, 20(2), 71-99. (Original publicado em 1988)

Smigay, K. V. (1989). Mulheres: (re) partidas e excluídas. Psicologia \& Sociedade, 4(7), 11-18.

Vives, L. \& Sité, S. (2010, junio). Negra española, negra extranjera: dos historias de una misma discriminación. Revista de Estudios de Juventude - Discriminaciones diversas en las personas jóvenes, 89, 163-186.

Wade, P. (2001). Raza e etnicidade em Latinoamérica. Quito: Abya Yala.

Waiselfisz, J. J. (2012). Mapa da Violência 2012 - A Cor dos Homicídios no Brasil. Rio de Janeiro: CEBELA - Centro de Estudos Latino Americanos/FLACSO; Brasília: SEPPIR/PR.

\section{Agradecimentos}

À CAPES e Fundação Carolina pelo apoio e financiamento. Edital MCT/CNPq/SPM-PR/MDA número 20/2010 - Relações de Gênero, Mulheres e Feminismo.

Submissão em: 04/11/2013

Revisão em: 30/03/2014

Aceite em: 20/04/2014

Raquel da Silva Silveira é psicóloga, doutora em Psicologia Social e Institucional/UFRGS.

Endereço: Rua Nunes, $\mathrm{n}^{\circ}$ 557, ap. 101. bairro Medianeira. Porto Alegre/RS, Brasil. CEP 90870-390

E-mail: raquelsilveira43@gmail.com

Henrique Caetano Nardi é Médico, doutor em sociologia, professor do Programa de Pós-Graduação em Psicologia

Social e Institucional/UFRGS.

E-mail: hcnardi@gmail.com

\section{Como citar:}

Silveira, R. S. \& Nardi, H. C. (2014). Interseccionalidade gênero, raça e etnia e a lei Maria da Penha. Psicologia \& Sociedade, 26(n. spe.), 14-24. 